\title{
Prognosis and improved outcomes in major depression: a review
}

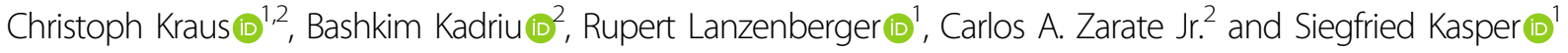

\begin{abstract}
Treatment outcomes for major depressive disorder (MDD) need to be improved. Presently, no clinically relevant tools have been established for stratifying subgroups or predicting outcomes. This literature review sought to investigate factors closely linked to outcome and summarize existing and novel strategies for improvement. The results show that early recognition and treatment are crucial, as duration of untreated depression correlates with worse outcomes. Early improvement is associated with response and remission, while comorbidities prolong course of illness. Potential biomarkers have been explored, including hippocampal volumes, neuronal activity of the anterior cingulate cortex, and levels of brain-derived neurotrophic factor (BDNF) and central and peripheral inflammatory markers (e.g., translocator protein (TSPO), interleukin-6 (IL-6), C-reactive protein (CRP), tumor necrosis factor alpha (TNFa)). However, their integration into routine clinical care has not yet been fully elucidated, and more research is needed in this regard. Genetic findings suggest that testing for CYP450 isoenzyme activity may improve treatment outcomes. Strategies such as managing risk factors, improving clinical trial methodology, and designing structured step-by-step treatments are also beneficial. Finally, drawing on existing guidelines, we outline a sequential treatment optimization paradigm for selecting first-, second-, and third-line treatments for acute and chronically ill patients. Well-established treatments such as electroconvulsive therapy (ECT) are clinically relevant for treatment-resistant populations, and novel transcranial stimulation methods such as theta-burst stimulation (TBS) and magnetic seizure therapy (MST) have shown promising results. Novel rapid-acting antidepressants, such as ketamine, may also constitute a paradigm shift in treatment optimization for MDD.
\end{abstract}

\section{Depression: a major and relentless burden}

Major depressive disorder (MDD) is the most common psychiatric disease and a worldwide leading cause of years lived with disability ${ }^{1,2}$. In addition, the bulk of suicides are linked to a diagnosis of MDD. Despite the high prevalence rate of MDD and ongoing efforts to increase knowledge and skills for healthcare providers, the illness remains both underdiagnosed and undertreated ${ }^{3}$. Many novel strategies with potentially broad impact are not yet ready for 'prime time', as they are either in early experimental stages or undergoing regulatory processes for approval.

\footnotetext{
Correspondence: Siegfried Kasper (siegfried.kasper@meduniwien.ac.at) ${ }^{1}$ Department of Psychiatry and Psychotherapy, Medical University of Vienna, Vienna, Austria

${ }^{2}$ Section on Neurobiology and Treatment of Mood Disorders, Intramural Research Program, National Institute of Mental Health, National Institutes of Health, Bethesda, MD, USA
}

This review sought to: (1) provide a synopsis of key factors associated with outcomes in MDD, and (2) synthesize the existing literature on novel treatment strategies for depression. A literature search was conducted using the search terms 'depression', 'antidepressant', 'outcome', 'predictor', '(bio)marker', 'treatment-resistant depression (TRD)', and 'chronic depression' in addition to combinations of these terms. The search was conducted in PubMed, Scopus, and Google Scholar with no restrictions on time period and concluded in October 2018. Notably, we defined 'outcomes' loosely, as either disease course (i.e., treatment resistance, chronic depression) or response/remission to treatment. changes were made. The images or other third party material in this article are included in the article's Creative Commons license, unless indicated otherwise in a credit line to the material. If material is not included in the article's Creative Commons license and your intended use is not permitted by statutory regulation or exceeds the permitted use, you will need to obtain permission directly from the copyright holder. To view a copy of this license, visit http://creativecommons.org/licenses/by/4.0/. 


\section{Prognostic variables for treatment outcomes in MDD}

Clinical variables

Clear evidence of an inverse relationship between duration of episode and treatment outcome (either response or remission) underscores the importance of early intervention in $\mathrm{MDD}^{4}$ (Table 1). In particular, replicable prospective and retrospective studies indicate that shorter duration of untreated disease-both in terms

Table 1 Candidate markers associated with treatment outcomes

\begin{tabular}{|c|c|c|}
\hline Marker & Outcome & References \\
\hline \multicolumn{3}{|l|}{ Clinical } \\
\hline Short duration of untreated disease & $\uparrow$ & $5-10$ \\
\hline Early response to treatment & $\uparrow$ & $9,12-15$ \\
\hline Lower baseline function & $\downarrow$ & $21,22,24$ \\
\hline $\begin{array}{l}\text { Psychiatric comorbidity (anxiety disorders, } \\
\text { PTSD, OCD, personality, cumulative) }\end{array}$ & $\downarrow$ & $26,40-46$ \\
\hline $\begin{array}{l}\text { Physical comorbidity (pain, cardiovascular, } \\
\text { neurological, cumulative) }\end{array}$ & $\downarrow$ & $47,48,50-56$ \\
\hline Stressful life events, childhood maltreatment & $\downarrow$ & $33-37$ \\
\hline Treatment resistance & $\downarrow$ & 28,109 \\
\hline \multicolumn{3}{|l|}{ Neuroimaging } \\
\hline Low baseline hippocampal volume_-sMRI & $\downarrow$ & 59,60 \\
\hline $\begin{array}{l}\text { High baseline activity in the anterior } \\
\text { cingulate cortex- fMRI, EEG, PET }\end{array}$ & $\uparrow$ & $60,70,71$ \\
\hline Microglial activation (TSPO-PET) & $\downarrow$ & $80-82$ \\
\hline rsfMRI in pathophysiologic regions & $\downarrow \uparrow$ & 69 \\
\hline $\begin{array}{l}\text { Key proteins of the serotonergic system } \\
\left(M A O-A, S E R T, 5-H T_{1 A}\right)\end{array}$ & $\downarrow \uparrow$ & $72-77$ \\
\hline \multicolumn{3}{|l|}{ Blood } \\
\hline $\begin{array}{l}\text { Plasma BDNF increases in response to } \\
\text { treatment }\end{array}$ & $\uparrow$ & 93 \\
\hline IL-6 decreases during treatment & $\uparrow$ & 83 \\
\hline High TNFa levels after treatment & $\downarrow$ & 86 \\
\hline High baseline CRP levels & $\downarrow$ & 84,85 \\
\hline \multicolumn{3}{|l|}{ Candidate genes $^{\mathrm{a}}$} \\
\hline BDNF_Val66Met Met allele in Asians & $\uparrow$ & 203 \\
\hline SLC6A4-5-HTTLPR, I-Allele & $\uparrow$ & 204 \\
\hline
\end{tabular}

$B D N F$ brain-derived neurotrophic factor, CRP c-reactive protein, EEG electroencephalography, IL-6 interleukin-6, OCD obsessive-compulsive disorder, PET positron emission tomography,

PTSD post-traumatic stress disorder

rsfMRI resting-state functional MRI, SLC6A4 solute carrier family 6 member 4 sMRI structural MRI, TNFa tumor necrosis factor alpha, TSPO translocator protein, 5-HT1A serotonin-1A receptor, MAO-A monoamine oxidase A, SERT serotonin transporter

${ }^{a}$ Representative examples with meta-analytic evidence of first and recurrent episodes-is a prognostic factor indicating better treatment response and better long-term outcomes $^{5-10}$, although not all studies have found such an association $^{11}$. Another important clinical variable is time to antidepressant response. For instance, one metaanalysis found that early improvement was positively linked to antidepressant treatment outcome in 15 of 16 studies $^{9}$. Early response to antidepressant treatment appears to occur independently of treatment modality ${ }^{12,13}$ or outcome parameters ${ }^{14,15}$. Another study found that early improvement in work productivity was a significant positive predictor of higher remission rates after three and seven months of treatment ${ }^{16}$. Similarly, imaging studies found that early response to treatment correlated with default mode network deactivation in the posterior cingulate $^{17}$, as well as thickening of gray matter in the anterior cingulate cortex $(\mathrm{ACC})^{18}$. Interestingly, two recent meta-analyses found that initial improvement was linked to response and outcome but failed to be associated with treatment resistance ${ }^{19,20}$. This suggests that TRDdefined loosely here as non-response to at least two adequate antidepressant trials-and chronic depression (roughly defined here as non-response to any treatment) may have similar response slopes in the earliest treatment stages.

In addition, lower baseline function and quality of lifeincluding longer duration of the current index episodehave been associated with lower remission rates to various types of antidepressant treatments ${ }^{21,22}$. This is in line with results from a previous study that found that baseline function predicted antidepressant response in TRD patients $^{23}$. Worse outcomes in more severely ill patients at baseline were also reported in elderly patients treated in primary-care settings ${ }^{24}$. In contrast, several controlled clinical studies found that elevated baseline severity correlated with improved response and remission rates ${ }^{25}$. Two naturalistic studies with broad inclusion criteria similarly found that remission correlated with higher baseline scores ${ }^{4,26}$. However, this discrepancy might be explained by variations in outcome according to parameter. It was noted earlier that studies that defined remission as percent change of baseline values might be biased in favor of higher baseline scores, while absolute endpoints (e.g., remission defined below a cutoff score) favor less sick patients ${ }^{4}$.

\section{Psychosocial variables}

The influence of sociodemographic factors such as age, age of onset, gender, and number of previous episodes on treatment outcome has been investigated with mixed results $^{4,27,28}$. One study found that females had higher remission rates ${ }^{21}$, but this was not confirmed by another prospective study ${ }^{27}$. Others have found that stress related to high occupational levels might impair outcomes ${ }^{29}$. The 
European "Group for the Study of Resistant Depression" (GSRD) multi-site study found that age at first treatment (i.e., early-onset and early treatment), age, timespan between first and last episode (i.e., duration of illness), suicidality, and education level were all important variables for outcome ${ }^{30}$. Notably, authors of long-lasting longitudinal studies have suggested that recall bias may influence the age of onset variable ${ }^{31,32}$; given the cognitive deficits associated with acute episodes of MDD, retrospective studies must hence address the factor of memory bias in data collection.

\section{Environmental stress and stressful life events (SLEs)}

High stress levels significantly influence outcomes in MDD patients who are prone to vulnerable states, such as those with high levels of neuroticism ${ }^{33,34}$. A meta-analysis found that history of childhood maltreatment was associated with elevated risk of developing recurrent and persistent depressive episodes, as well as with lack of response or remission during treatment ${ }^{35}$. Another metaanalysis confirmed the detrimental impact of childhood maltreatment (emotional physical or sexual maltreatment or neglect) as a predisposing risk factor for severe, earlyonset, and treatment-resistant depression ${ }^{36,37}$. Studies also found gender-specific effects; in particular, at lower stress levels females were at higher risk of MDD than males $^{34}$. Moreover, twin studies have suggested a differential reactivity of gender in response to type of $\mathrm{SLE}^{38}$. For instance, a treatment study using escitalopram and nortriptyline investigated the association between number of SLEs (e.g., job loss, psychological trauma, loss of a loved one) and antidepressant treatment. Subjects with more SLEs exhibited greater cognitive symptoms at baseline but not significantly more mood or neurovegetative symptoms. These patients also had greater cognitive symptom reduction in response to escitalopram but not nortriptyline ${ }^{39}$. This suggests that SLEs may have a cognitive domain-specific impact in MDD, but more data are needed to elucidate this issue.

\section{Psychiatric and physical comorbidities}

Psychiatric comorbidity has been shown to influence outcome in both treated and untreated patients ${ }^{40,41}$. Studies have found that elevated baseline anxiety symptoms or comorbid anxiety disorder are associated with worse antidepressant response to first-line selective serotonin reuptake inhibitors (SSRIs) or second-line treatment strategies ${ }^{42,43}$. Worse outcomes have also been reported for MDD patients with comorbid drug or alcohol use disorders, post-traumatic stress disorder (PTSD), and "double depression" (depression and dysthymia) ${ }^{26,41}$. Data from the Sequential Treatment Alternatives to Relieve Depression (STAR*D) study, which included patients who were seeking medical care in routine medical or psychiatric outpatient treatment, indicate that roughly one-third (34.8\%) of all MDD patients are free of any comorbidity; the most frequent comorbid Axis-I disorders are social phobia (31.3\%), generalized anxiety disorder (23.6\%), PTSD (20.6\%), and obsessive-compulsive disorder $(14.3 \%)^{21}$. A large recent study found that clinically diagnosed personality disorder was associated with negative outcomes (with regard to remission and persistent depressive symptoms) six months after diagnosis in MDD subjects enrolled in primary care ${ }^{44}$. Moreover, meta-analytic studies indicate that comorbid personality disorder increases the likelihood of poorer outcomes ${ }^{45,46}$; it should be noted, though, that negative studies have also been reported ${ }^{40}$.

MDD and several physical diseases-including cardiovascular disease and diabetes-appear to have bidirectional effects on disease trajectory ${ }^{47,48}$, yet pathophysiologic links are most likely complex and have to be elucidated. In addition, depression appears to be linked to hormonal diseases, including hypothyroidism ${ }^{49}$. A number of physical disabilities and medical comorbidities have been shown to significantly impact outcome measures in $\mathrm{MDD}^{50}$, particularly in elderly subjects ${ }^{51}$. This connection appears to be relevant at any stage of the disease, as number of physical comorbidities did not separate TRD from non-TRD patients ${ }^{52}$. Links between MDD and pain have also been noted; subjects with elevated levels of baseline pain due to chronic conditions had longer depressive episodes, delayed remission ${ }^{53}$ and, most importantly, elevated suicide risk ${ }^{54,55}$. Interestingly, a prospective, 12-month study of older patients found that elderly patients with atrial fibrillation exhibited better remission rates $^{56}$. Patients with chronic pulmonary diseases had worse outcomes in uncontrolled treatment settings than those without these diseases. This difference was absent in the intervention group, in which depression care managers helped physicians with guidelineconcordant recommendations and helped patients adhere to treatment ${ }^{56}$. Further longitudinal studies on shared pathophysiology with physical diseases are needed to confirm such associations.

\section{Neuroimaging markers of treatment outcomes}

Structural markers of antidepressant treatment outcomes suggest that hippocampal volumes are related to response and remission ${ }^{57,58}$. One study found that low baseline hippocampal volumes were related to impaired treatment outcomes after 3 years ${ }^{59}$; a meta-analysis confirmed that low baseline hippocampal volumes are associated with negative outcomes ${ }^{60}$. However, negative studies have also been reported ${ }^{61,62}$. The volume of other brain regions, including the anterior cingulate or orbitofrontal cortices, have also been shown to be decreased in MDD subjects ${ }^{63}$, but more longitudinal neuroimaging 
trials with antidepressants are needed to clarify this association. Interestingly, several studies, including one meta-analysis ${ }^{64}$, found significant hippocampal volume increases after $\mathrm{ECT}^{65-67}$, although the relationship to antidepressant response has yet to be confirmed ${ }^{64,68}$.

The largest functional magnetic resonance imaging (fMRI) study of MDD patients conducted to date reported neurophysiological subtypes based on connectivity patterns within limbic and frontostriatal brain areas ${ }^{69}$. In subset analyses, connectivity patterns plus subtype classifications predicted response to repetitive transcranial magnetic stimulation (rTMS) treatment with higher accuracy $(89.6 \%)$ than clinical characteristics alone. Other task-based and resting-state fMRI studies found that ACC activity (including pregenual activity) predicted treatment response $^{70}$, a finding corroborated by an expanded electroencephalography study ${ }^{71}$ as well as a meta-analysis ${ }^{60}$. While these interesting results suggest that fMRI measures could ultimately help classify biological subtypes of depression, these methods are far from ready for clinical application and results will have to be reproduced. However, given its easy implementation and the short time needed to acquire measurements, fMRI appears to be a promising tool for identifying imaging biomarkers.

Positron emission tomography (PET) studies have identified altered serotonin-1A (5- $\left.\mathrm{HT}_{1 \mathrm{~A}}\right)$ receptor and 5-HT transporter (SERT) binding potentials, an index of protein concentration, at baseline and in TRD patients ${ }^{72-75}$. Most of these results found reduced baseline SERT levels and elevated baseline $5-\mathrm{HT}_{1 \mathrm{~A}}$ heteroreceptors in MDD patients (depending on PET methodology for $5-\mathrm{HT}_{1 \mathrm{~A}}$ ); nonremitters had lower $5-\mathrm{HT}_{1 \mathrm{~A}}$ autoreceptor binding in the serotonergic raphe nuclei ${ }^{75}$, as well as lower SERT ${ }^{76}$. Reduced global $5-\mathrm{HT}_{1 \mathrm{~A}}$ receptor binding has also been observed after $\mathrm{ECT}^{77}$. High costs, technical and methodological challenges, lack of dedicated PET centers with ${ }^{11} \mathrm{C}$ radiochemistry, small sample sizes, small effect sizes, and unclear cutoff values have heretofore prevented the broader clinical application of these tools in MDD compared to disorders such as Alzheimer's and Parkinson's disease. An earlier $\left[{ }^{18}\right.$ F]FDG PET study of unmedicated MDD patients was consistent with the aforementioned fMRI results, demonstrating increased glucose turnover in the orbitofrontal and posterior cingulate cortices and amygdala and decreased turnover in the subgenual ACC and dorsolateral prefrontal cortex ${ }^{78}$. A later study corroborated these results and found that glucose turnover was differentially affected by cognitive behavioral therapy or venlafaxine ${ }^{79}$. Interestingly, several studies detected microglial activation by labeling translocator protein (TSPO) with PET, using TSPO radioligands like ${ }^{18}$ F-FEPPA. Microglial activation is closely linked to brain tissue damage, traumatic brain injury, neuroinflammation, and increased metabolic demands. Increased TSPO binding in MDD patients has been observed in the ACC, insula, and prefrontal cortex ${ }^{80}$. In addition, TSPO binding has also been shown to positively correlate with length of illness and time without antidepressant treatment, and to negatively correlate with SSRI treatment ${ }^{80}$. Elevated TSPO levels in unmedicated, acutely ill MDD patients have now been reported in at least two independent datasets ${ }^{81,82}$. However, TSPO-positive MDD patients may reflect a specific subtype (i.e., associated with neuroinflammation) and may, thus, respond better to treatments that target neuroinflammation. For a graphical summary of these findings see Fig. 1.

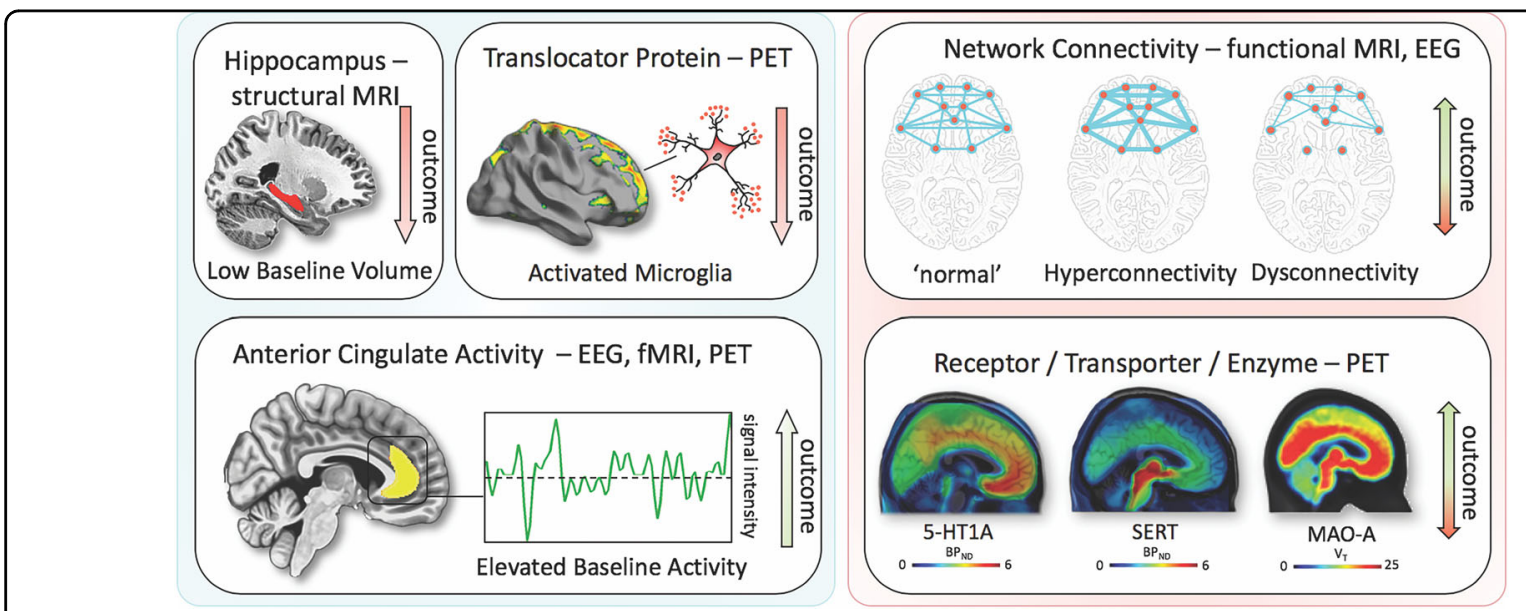

Fig. 1 Summary of imaging findings and their relationship with outcome. Imaging findings exhibiting unidirectional (left) relationships with outcome in MDD vs. bidirectional (right). fMRl, functional magnetic resonance imaging; PET, positron emission tomography; EEG

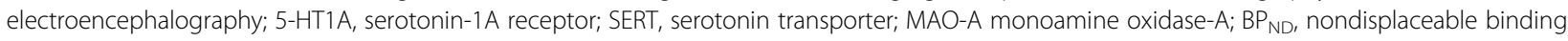
potential; $V_{T}$, volume of distribution 


\section{Blood-based markers of disease outcomes}

Consistent with neuroinflammatory processes, elevated levels of C-reactive protein (CRP), tumor necrosis factor alpha (TNFo), and interleukin-6 (IL-6) have been reported in a subset of MDD patients. In particular, elevated levels of CRP, a well-established marker of increased proinflammatory state in blood, was shown to be associated with MDD and increased risk for psychological distress in cross-sectional samples of the general population $^{83}$. A longitudinal study found that lower CRP levels were associated with quicker response to SSRIs, an association not observed for SSRI-bupropion combination therapy ${ }^{84}$. Interestingly, elevated CRP levels have been shown to be more pronounced in female versus male MDD patients ${ }^{85}$. Similar findings have been observed for IL-6 and TNF $\alpha$. One meta-analysis found that all three were significantly elevated at baseline in MDD patients, but their treatment trajectories differed ${ }^{86}$; IL-6 levels decreased with antidepressant treatment, but outcomes were indistinguishable. In the same meta-analysis, persistingly high TNF $\alpha$ levels identified TRD patients ${ }^{86}$. Notably, heterogeneity was high within the pooled studies. Another study noted that levels of acute phase protein complement C3 significantly differentiated between atypical and melancholic MDD subtypes ${ }^{87}$. MDD patients have also been shown to have altered levels of peripheral adipokines and bone inflammatory markers; these deficits were corrected with ketamine treatment ${ }^{88,89}$.

Given the importance of neuroplasticity in the pathophysiology and treatment of depression, interest has grown in studying brain-derived neurotrophic factor (BDNF), a neurotrophin involved in the structural adaptation of neuronal networks and a prerequisite for neuronal reactions to stressors. BDNF blood levels most likely stem from peripheral tissue. While these peripheral levels are linked to central levels, the question of whether BDNF is actively transported through the blood-brain barrier remains controversial ${ }^{90}$. Compelling evidence suggests that BDNF levels are decreased at baseline in MDD patients and elevated in response to pharmacological ${ }^{90,91}$ treatments as well as $\mathrm{ECT}^{92}$. A meta-analysis found that increased BDNF levels in response to treatment successfully stratified responders and remitters compared to nonresponders ${ }^{93}$.

\section{Outcome and genetic and epigenetic links}

Heritable risk for MDD is between 30 and 40\%, with higher rates in women. A large, collaborative genomewide association study (GWAS) detected 44 significant loci associated with $\mathrm{MDD}^{94}$. Specific analyses identified neuronal genes (but not microglia or astrocytes), geneexpression regulating genes (such as RBFOX1), genes involved in gene-splicing, as well as genes that are the targets of antidepressant treatment. The authors suggested that alternative splicing could lead to shifts in the proportion of isoforms and altered biological functions of these proteins ${ }^{94}$.

Hypothesis-driven approaches with candidate genes have provided initial insights into the influence of singlenucleotide polymorphisms (SNPs). It is beyond the scope of this manuscript to review the large number of candidate genes; here, we outline only several representative genes (see Table 1 for meta-analytic evidence of treatment outcomes). These include synaptic proteins involved in stress response, antidepressant binding structures, or neuroplasticity (e.g., CRH receptor 1 (CRHR1)), the sodiumdependent serotonin transporter (SLC6A4), and $B D N F^{95}$. The aforementioned multicenter GSRD study also found that combining clinical and genetic variables explained antidepressant response better than SNPs alone in a random forest algorithm ${ }^{96}$. In that study, regulatory proteins such as ZNF804A (associated with response) and CREB1 (associated with remission), as well as a cell adhesion molecule (CHL1, associated with lower risk of TRD), were linked to antidepressant treatment outcomes. Another interesting candidate gene is FK506 binding protein 5 (FKBP5), which was found to moderate the influence of standard treatments in an algorithm lasting up to 14 weeks ${ }^{97}$; FKBP5 is known to influence HPA axis reactivity $^{98}$, treatment response ${ }^{99}$, and epigenetic mechanisms in response to environmental stressors ${ }^{100}$. Another relevant avenue of research is drug-drug interactions and gene isoforms in the cytochrome P450 pathway (CYP450), which could account for insufficient amounts of a given drug reaching the brain or, conversely, result in exceedingly high plasma values, making subjects more vulnerable to treatment side effects ${ }^{101,102}$. Several commercially available kits categorize patients according to their phenotypic status (e.g., CYP2D6, 2C19, CYP3A4). This led to the introduction of phenotype categories-"poor", "intermediate", "extensive (normal)", and "ultrarapid" metabolizers-based on CYP450 isoenzyme status and their relationship to plasma levels at fixed doses ${ }^{102}$. A large naturalistic study of CYP2C19 isoforms found that treatment success with escitalopram was less frequent in "poor" (CYP2C19Null/Null) and "ultrarapid" metabolizers (CYP2C19*1/*17 or CYP2C19*17/*17) ${ }^{103}$.

\section{Clinical subgroups, TRD, and treatment outcomes}

While some studies have suggested that depressive subtypes in MDD-including anxious, mixed, melancholic, atypical, and psychotic depression-respond differently to antidepressant treatment, this literature is mixed. For instance, some studies found that melancholic patients initially present with high levels of severity and may respond less well to SSRI treatment than to venlafaxine or tricyclic antidepressants ${ }^{104}$, but other studies did not support this finding ${ }^{105}$. No association was found 
between subgroups and clinical outcomes in a parallel design, uncontrolled study investigating sertraline, citalopram, and venlafaxine ${ }^{106}$, which found that near equal percentages of patients who met criteria for a pure-form subtype (39\%) also had more than one subtype (36\%), making these psychopathological subtypes difficult to classify.

It should be noted that treatment success might have more discriminatory power for identifying subgroups than psychopathological subgroup stratification. Although a wide range of definitions exists specifying the number of failed trials necessary to diagnose TRD ${ }^{107}$, the core definition of TRD centers around a lack of improvement in response to consecutive, adequate antidepressant treatments. Resistance occurs at alarmingly high rates and is thought to affect $50-60 \%$ of all treated patients ${ }^{107}$. Unsurprisingly, this group of patients has dramatically worse outcomes than those who respond to antidepressants, and factors that are associated with TRD overlap with many of those presented above ${ }^{28}$. Crosssectional data from the GSRD ${ }^{108}$ identified a number of risk factors linked to TRD, including comorbidity (particularly anxiety and personality disorders), suicide risk, episode severity, number of hospitalizations, episode recurrence, early-onset, melancholic features, and nonresponse at first treatment ${ }^{28}$. Most importantly, TRD is life-threatening, and associated with a two- to threefold increased risk of suicide attempts compared to responding patients, and a 15-fold increased risk compared to the general population ${ }^{109}$. Taken together, the evidence indicates that TRD patients need special attention, as outcomes in these individuals are significantly worse.

\section{Novel and existing strategies to improve treatment outcomes}

Early identification, prevention, and early treatment

Numerous programs for suicide prevention exist ${ }^{110}$, and recognizing acute depressive symptoms is just one of many important facets of such work. Screening tools for early identification of depressed patients can be helpful ${ }^{111}$, and such instruments can start with as few as two itemsfor instance, the Patient Health Questionnaire- $2^{112}$ or Ask Suicide-Screening Questions (asQ'em) $)^{113}$-and proceed to more detailed instruments if initial screens are positive. Positive screening should be followed by a diagnostic interview to determine whether patients meet criteria for $\mathrm{MDD}^{111}$. In the general population, two large independent studies that used only clinical variables were nevertheless able to accurately predict depression within 1-3 years ${ }^{114}$. In addition, long-term monitoring of vulnerable subjects with known SLEs may further improve the ability to identify at-risk individuals early in their course of illness. As noted above, duration of untreated disease is a negative predictor of treatment outcomes. Because the advantages of early intervention in MDD have been demonstrated $^{115}$, efforts to achieve early treatment might also help slow disease progression in individuals with TRD; however, this hypothesis has not been sufficiently tested.

\section{Modeling environmental impact on predisposition}

As noted above, severe SLEs constitute an important risk factor. Elegantly designed studies have demonstrated that genetic predisposition, in concert with SLEs, might account for increased vulnerability to $\mathrm{MDD}^{100}$. In this manner, the presence of 'weak alleles' in candidate genes such as $B D N F, S E R T$, and others would be increasingly detrimental in the presence of SLEs ${ }^{116,117}$. However, studies have been quite inconsistent and yielded small effect sizes, including a negative result in 252 patients enrolled in the GSRD study ${ }^{18}$. It should be noted that counterregulatory mechanisms or resilience factors, such as social support, may exist that counter SLEs. Nevertheless, preliminary research suggests that the impact of SLEs on MDD may depend on measurable factors such as gender and the timing of exposure ${ }^{119}$. Both genes and the environment are complex systems with frequent opportunity for interaction and elaborate compensatory mechanisms. While the complexity of genetic susceptibility in MDD can be tackled through enormous collaborative projects $^{94}$, the interactions between genetic susceptibility and environmental factors have yet to be determined. Properly powered genexenvironment interaction projects may exceed current research capabilities, and large longitudinal studies will certainly be needed ${ }^{120}$.

\section{Developing markers for subgroup identification and disease course}

Pioneering research on biological differences-for instance, between patients with atypical versus melancholic depression-suggests differential HPA axis or autonomous nervous system reactivity ${ }^{121,122}$, though the subtype results have been only moderately consistent across time and are prone to low group specificity ${ }^{123-125}$. However, at least one study demonstrated the more reliable stability of extreme types over a 2 -year period ${ }^{87}$. Interestingly, one study found that individuals with atypical depression had significantly higher body-mass index, waist circumference, levels of inflammatory markers, and triglyceride levels, and lower levels of high-density lipid cholesterol than those with melancholic depression or controls $^{126}$. Using fMRI and biological variables, another study found that MDD subjects could be divided into low/ high appetite groups with distinctive correlations between neuronal activity and endocrine, metabolic, and immune states $^{127}$. Other research groups have tried to overcome conventional psychopathological subgroups and model biotypes using resting-state $\mathrm{fMRI}^{69}$. Molecular and 
functional neuroimaging, as well as epigenetic studies, are promising approaches for separating subgroups and may be better suited to identifying screening markers (see Fig. 2) that are exclusively valid in certain subgroups with higher predictive power.

These approaches highlight the feasibility of linking and stratifying psychopathological categories with biological variables, a goal further supported by the Research Domain Criteria (RDoc), which seek to link dimensions of observable behavior with neurobiological systems ${ }^{128}$. In the search for biomarkers, subgroup- or domain-specific classifications using unidimensional variables might improve subgroup stratification ${ }^{129}$. Moreover, applying markers to other categories could boost the utility of existing markers that have failed in any given category (see Fig. 2 for established markers). As a field, the focus is largely on staging and prediction markers, but 'predisposition' or 'recurrence' markers may equally be worth

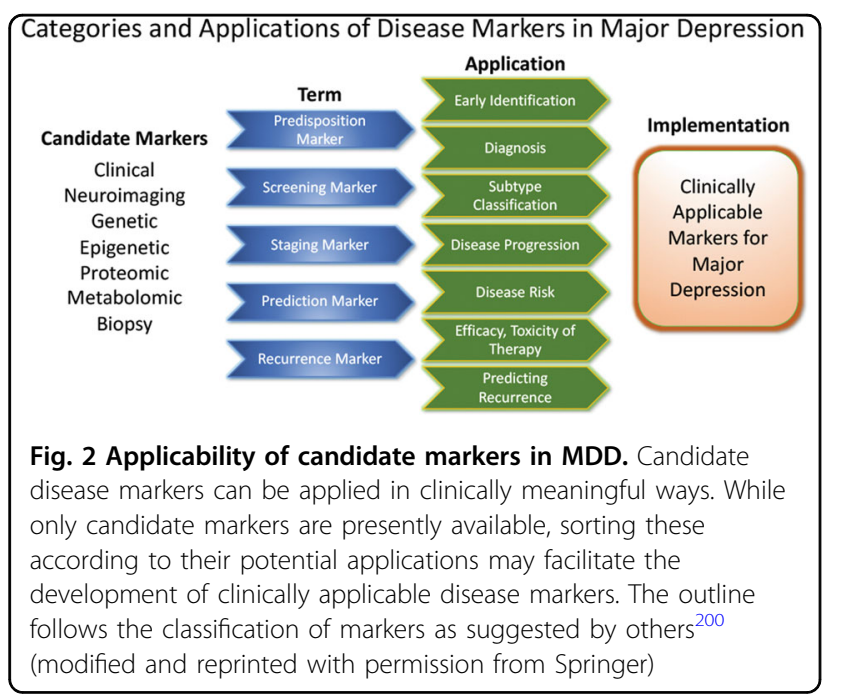

investigating. Presently, however, the relative lack of biologically defined MDD subgroups and their stratification are key obstacles to finding and establishing treament outcome predictors appropriate for broader clinical applications.

The most important outcome of successful subgroup stratification and staging markers would be that patients and their relatives would receive valuable information at treatment onset about how their disease is likely to improve or worsen. Toward this end, the development of staging methods provides promising solutions. Currently, at least five different methods exist ${ }^{130}$ that, to date, have not been evaluated thoroughly enough for clinical implementation. Continuous variables-as obtained by the Maudsley Method and Massachusetts General Hospital Staging Model-appear to provide greater staging advantages than categorical variables. It should be noted here that data indicate that research in severely ill, suicidal, and TRD subjects is safe to conduct in controlled inpatient settings ${ }^{131}$. Presently, patients in various stages of disease and/or treatment history are lumped together and compared in statistical analyses. We propose that staging should be more thoroughly integrated into clinical trial design.

\section{Algorithm- and guideline-based treatments}

Despite the availability and distribution of a variety of expert-based guidelines, only a fraction of patients are actually treated according to guidelines ${ }^{132}$ (see Table 2 for current guidelines ( $\leq 10$ years)). New guidelines - particularly for TRD - and more rigorous implementation of guideline-based care are needed. Improvements in currently available treatments have been conducted using treatment algorithms and following sequential treatment strategies, with standardized instructions for therapeutic decision-making. In the past two decades, large,

Table 2 Currently available guidelines and consensus papers

\begin{tabular}{|c|c|c|}
\hline Name/Organization & URL $^{\mathrm{a}} /$ reference & Country, Year \\
\hline $\begin{array}{l}\text { World Federation of Societies of Biological Psychiatry (WFSBP) consensus papers } \\
\text { and treatment guidelines }\end{array}$ & www.wfsbp.org & $\begin{array}{l}\text { Worldwide, 2015, 2013, } \\
2007\end{array}$ \\
\hline American Psychiatric Association Practice Guidelines (APA) & $\begin{array}{l}\text { www.psychiatryonline.org/ } \\
\text { guidelines }\end{array}$ & USA, 2010 \\
\hline British Association for Psychopharmacology & www.bap.org.uk/guidelines & UK, 2015 \\
\hline Canadian Network for Mood and Anxiety Treatments (CANMAT) & www.canmat.org & Canada, 2016 \\
\hline $\begin{array}{l}\text { Institute for Clinical Systems Improvement (ICSI) Healthcare Guideline for Major } \\
\text { Depression in Adults in Primary Care }\end{array}$ & www.icsi.org & USA, 2016 \\
\hline S3 Guidelines & www.leitlinien.de/nvl/depression & Germany, 2017 \\
\hline Therapy resistant depression guideline & www.oegpb.at & Austria, 2017 \\
\hline
\end{tabular}

${ }^{\mathrm{a}}$ As of October 2018 
collaborative studies using treatment-based algorithms have introduced standardized, sequential treatments; these include the Texas Medication Algorithm Project ${ }^{133}$, the STAR*D trial ${ }^{21}$, and the German algorithm project ${ }^{134}$. Indeed, evidence suggests that algorithm-based treatments improve treatment outcomes ${ }^{135}$ and are cost effective $^{136}$. Here, we considered current clinical treatment guidelines to create a sequential treatment optimization scheme of recommended treatments. While there is no fixed time-frame, first- and second-line treatments are recommended sequentially during the first episode and within 3 months (see Fig. 3, which also illustrates the need for more third- and fourth-stage treatment options). Figure 4, illustrates potential reasons for "pseudoresistance" ${ }^{42}$ that should be ruled out during this time-frame.

\section{Reducing placebo response in clinical trials while harnessing placebo effects in clinical treatment}

The issue of placebo response in antidepressant trials has become increasingly important ${ }^{137,138}$. Indeed, the contribution of placebo effects to early response needs to be systematically studied in order to disentangle biological therapy-induced effects from psychologically induced effects. Strikingly, in the brain, anatomically similar regions that mediate placebo response are affected by MDD (for a comprehensive review, see ref. ${ }^{139}$ ). Several mechanisms contribute to placebo response, including patients' expectations of benefits, behavioral conditions, and the quality of patient-physician interactions ${ }^{139}$. Strategies for reducing placebo response could lead to better discrimination between effective treatments in clinical trials; such strategies include extending trial duration, excluding placebo responders by including a placebo runin, or using randomized run-in and withdrawal periods $^{138,139}$. Others have suggested using more thorough criteria to select study participants ${ }^{140}$. On the other hand, when antidepressant agents are used clinically, placebo effects must be taken advantage of by harnessing patients' expectations and learning mechanisms to improve treatment outcomes ${ }^{141}$.

\section{Novel antidepressant treatments}

The recent discovery that glutamatergic-based drugs are uniquely capable of rapidly and robustly treating mood disorders has ushered in a new era in the quest to develop novel and effective antidepressants ${ }^{142-144}$. In this regard, the prototypic glutamatergic modulator ketamine has catalyzed research into new mechanistic approaches and offered hope for the development of novel, fast-acting antidepressants. While ketamine's underlying mechanism of action remains the subject of active investigation, several theories have been propsed ${ }^{144}$. These include $\mathrm{N}$ methyl-D-aspartate receptor (NMDAR)-dependent mechanisms, such as the inhibition of NMDARs on gamma aminobutyric acid (GABA)-ergic interneurons, the inhibition of spontaneous NMDAR-mediated transmission, the inhibition of extrasynaptic NMDARs, the inhibition of lateral habenula neurons, and $G_{A B A}$ receptor expression/function ${ }^{144}$. Substantial evidence also supports additional NMDAR-independent mechanisms, including the stabilization of glutamate release/excitatory transmission, active metabolites such as hydroxynorketamine, regulation of the dopaminergic system, G-alpha subunit translocation, and activation of cyclic adenosine monophosphate, as well as potential sigma-1 and mu-opioid receptor activation ${ }^{145}$. Among those theories, a leading hypothesis remains that NMDAR antagonism increases BDNF synthesis, a process mediated by decreased phosphorylation of eukaryotic elongation factor-2 and the subsequent activation of the mammalian target of rapamycin pathway by BDNF activation of the TrkB receptor ${ }^{146,147}$. These putative mechanisms of action are not mutually exclusive and may complement each other to induce potentiation of excitatory synapses in affective-regulating brain circuits, resulting in improved depressive symptoms.

\section{Ketamine}

The initial serendipitous discovery that a single, subanesthetic-dose ketamine infusion has rapid-acting antidepressant effects in $\mathrm{MDD}^{148}$, a finding subsequently confirmed by numerous randomized trials, has been hailed as one of the most important discoveries in psychiatry in the last decades ${ }^{149}$. The initial proof-of-concept studies demonstrated that a single dose of ketamine $(0.5 \mathrm{mg} / \mathrm{kg}, \mathrm{IV})$ administered over $40 \mathrm{~min}$ led to rapid, robust, and relatively sustained antidepressant effects in TRD-both MDD ${ }^{150-153}$ and bipolar depression ${ }^{154,155}$. In research settings, studies of TRD patients found response rates of $>70 \%$ within $24 \mathrm{~h}$ post-infusion ${ }^{153}$, with about $50-70 \%$ of participants exhibiting a variable duration of response $\mathrm{e}^{156,157}$. Ketamine has also been shown to be superior to any blinding counterpart ${ }^{158}$. Off-label ketamine use has also been associated with significant and rapid (one to four hours) antisuicidal effects ${ }^{150,159,160}$, a finding supported by a large, recent metanalysis showing that ketamine exerted rapid (within hours) and sustained (up to 7 days) improvements in suicidal thoughts compared to placebo ${ }^{161}$.

\section{Esketamine hydrochloride}

The ketamine enantiomer esketamine received approval by the FDA for TRD and is currently undergoing further Phase III clinical trials. A Phase II, 10-week, clinical trial of flexibly dosed intranasal esketamine $(28 \mathrm{mg} / 56 \mathrm{mg}$ or $84 \mathrm{mg}$ ) found that, in TRD patients, this agent demonstrated rapid and clinically relevant improvements in 


\section{Sequential Treatment Optimization Scheme}
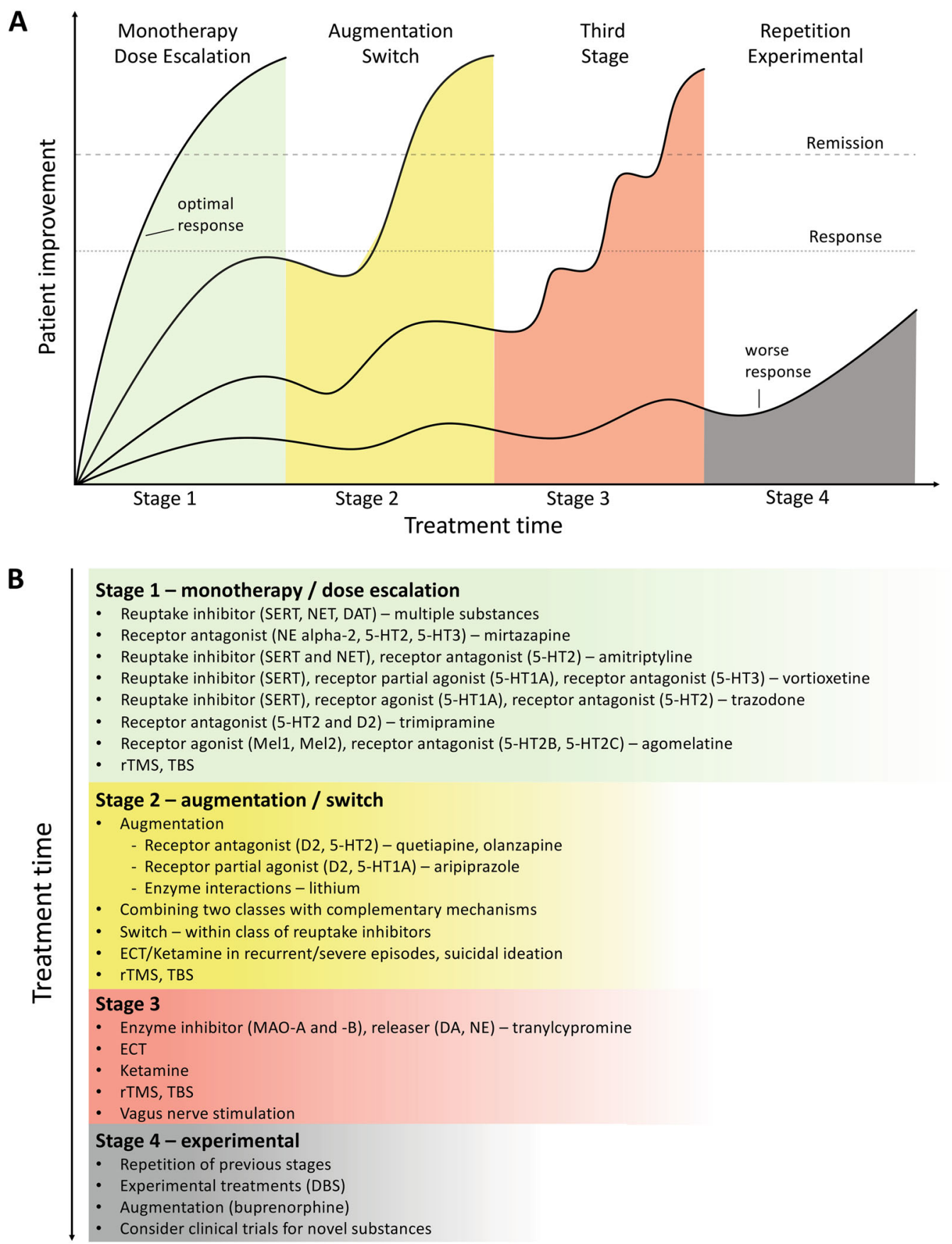

Fig. 3 Sequential treatment optimization scheme for major depression. A sequential treatment optimization scheme was generated based on antidepressant treatment guidelines (see Table 2). Treatment optimization is possible for patients being treated for the first time but also for patients with insufficient response to first- or second-stage therapies. a Treatment response curves for four common types of patients highlight the importance of sequentially introducing the next step upon non-response to previous steps. $\mathbf{b}$ Currently available treatments are listed in neuroscience-based nomenclature ${ }^{201}$ with treatment lines corresponding to improvement curves in a. Although current classifications vary, patients classified as having treatment-resistant depression (TRD) are eligible for second- or third-stage therapies. 5-HT1A and similar: serotonin receptor subtypes; DBS: deep brain stimulation; DAT: dopamine transporter; D2: dopamine receptor D2; ECT: electroconvulsive therapy; MAO: monoamine oxidase; NET: noradrenaline transporter; SERT: serotonin transporter; TBS: theta-burst stimulation; rTMS: repetitive transcranial magnetic stimulation; DA: dopamine; NE: norepinephrine. 


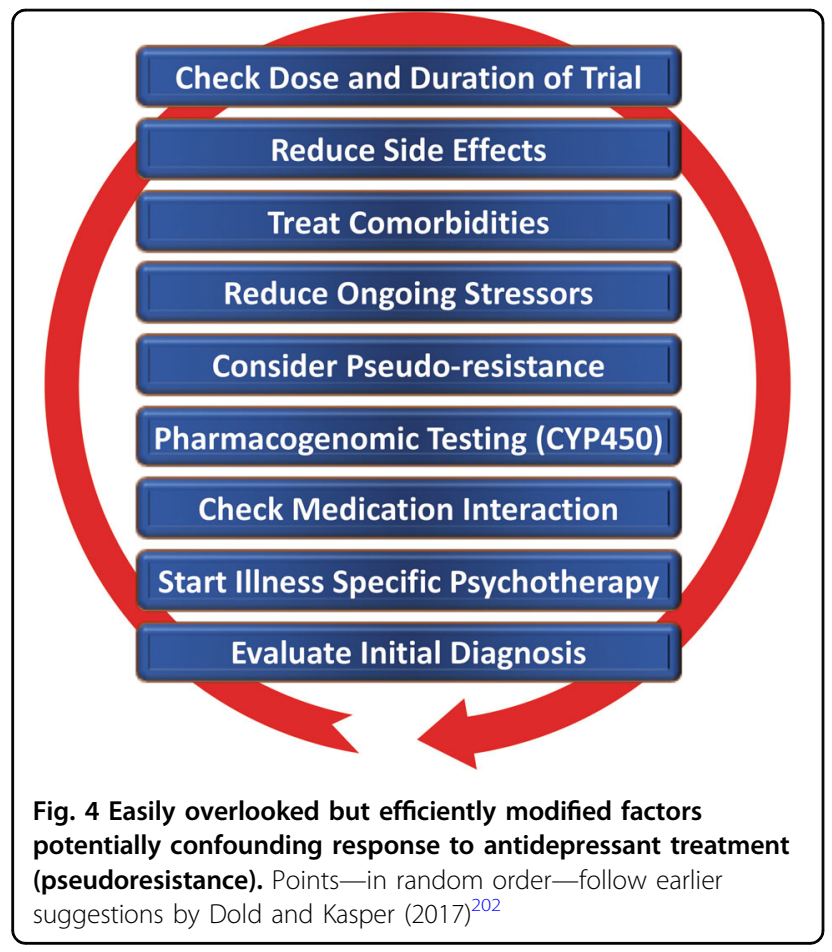

depressive symptoms compared to placebo ${ }^{162}$. Strikingly, $65 \%$ of TRD patients met response criteria through Day 57. In another Phase II proof-of-concept, multi-site, 4week, double-blind study, standard treatment plus intranasal esketamine $(84 \mathrm{mg})$ was compared to standard treatment plus placebo in individuals with MDD at imminent risk of suicide ${ }^{163}$. The authors found a rapid antisuicidal effect, as assessed via the MontgomeryÅsberg Depression Rating Scale Suicide Item score at $4 \mathrm{~h}$.

\section{Other rapid acting and novel antidepressants}

Based on the success of ketamine, other rapid-acting or novel antidepressant substances within the glutamatergic/ GABA neurotransmitter systems are being developed, several of which are in Phase III clinical trials. A prototype novel substance is AV-101 (L-4-cholorkynurenine). This is a potent selective antagonist at the glycine-binding site of the NMDAR NR1 subunit and has demonstrated antidepressant-like effects in animal models, while human Phase II studies are currently ongoing ${ }^{164}$. Brexanolone is a formulation of the endogenous neurosteroid allopregnanolone, which modulates neuronal activation of $\mathrm{GABA}_{\mathrm{A}}$ receptors and has met positive endpoints in Phase III, leading to FDA approval for postpartum depression. A comparable substance is under development for $\mathrm{MDD}^{165}$. In addition, serotonergic agonists have been studied as our understanding of their mechanism of action (e.g., their effects on glutamate release or plasticity) has increased $^{166}$. Encouraging results have been seen for the serotonin $2 \mathrm{~A}$ receptor agonist psilocybin ${ }^{167}$, but these findings need to be replicated in larger systematic clinical trials. Initial positive trials of add-on agents-such as buprenorphine ${ }^{168,169}$, rapastinel ${ }^{170}$, or scopolamine ${ }^{145}$ have also been conducted. However, it is beyond the scope of this manuscript to review all of these findings, and we refer the interested reader to recent comprehensive reviews of this subject ${ }^{144,145,165,171}$.

\section{Transcranial stimulation paradigms}

In contrast to pharmaceutical treatments that exert their efficacy at the molecular level, electrical stimulation techniques target entire neuronal circuits. TMS of the (left) dorsolateral prefrontal cortex has been FDAapproved since 2008 to treat depression in patients who failed to respond to one standard antidepressant treatment. Apart from transient local skin and muscle irritation at the stimulation site and headaches, it is a very safe technique with few side effects. Studies have repeatedly demonstrated the superiority of rTMS over sham procedures, though effect sizes have been moderate ${ }^{172-174}$. Initial studies suggest that rTMS is also effective in TRD but the data are too few to draw definitive conclusions ${ }^{175,176}$. Improvements in rTMS techniques known as theta-burst stimulation (TBS) provide significantly shortened treatment times ( $3 \mathrm{~min}$ for TBS versus $37 \mathrm{~min}$ for rTMS) and hence allow more patients to be treated per day. A large non-inferiority trial of 414 moderately resistant MDD patients found that TBS was at least as effective as rTMS in reducing depressive symptoms ${ }^{177}$.

\section{Electroconvulsive therapy (ECT)}

Regarded as the 'gold standard', ECT has been successfully used for many years to treat severe TRD and exhibits both relatively rapid and sustained onset of efficacy; approximately $50 \%$ of all patients reach response criteria at the third treatment, typically within 1 week. It is also one of the most effective antidepressant therapies ${ }^{178}$, yielding response rates of $\sim 80 \%$, remission rates of $\sim 75 \%{ }^{179}$, and antisuicidal effects ${ }^{180}$. Remission is achieved by about $30 \%$ of patients within six ECT sessions ${ }^{179}$. ECT also reduces the risk of readmission ${ }^{181}$ and is likewise safe to use in depressed elderly subjects ${ }^{182}$. The side effects of ECT include intermediate disorientation, impaired learning, and retrograde amnesia, all of which usually resolve $^{183}$. The optimal anatomic location of the stimulus electrodes is a topic of current debate ${ }^{184,185}$. Recent evidence suggests that all three methods for electrode placement (bifrontal, bitemporal, and unilateral) show clinically significant effects ${ }^{186}$. While no difference in cognitive side effects was observed, bitemporal placement should be considered the first-line choice for urgent clinical situations. Despite its clinical efficacy, ECT remains underutilized. Its use is declining ${ }^{187}$ because it needs to be administered in hospital settings under 
anesthesia, and partly because of misleading portrayals of the procedure itself. Adjusting the dose of electrical stimuli (e.g., through refined electrode placement or individually adjusted pulse amplitudes) may improve ECT's side effect profile.

\section{Magnetic seizure therapy (MST)}

MST uses high doses of rTMS to induce seizures ${ }^{188}$. The electromagnetically induced electrical field generated by MST is unifocal and variable, as there are individual differences in the degree to which the skull provides electrical resistance ${ }^{189}$. As an advantage over ECT, MST is associated with a more superficial stimulation, which exerts less impact on the medial-temporal lobe where cognitive side effects are thought to be elicited. To date, few research sites across the world have used MST, with a concomitant dearth of open-label trials. Nevertheless, the preliminary treatment data suggest that results obtained with MST are similar to those obtained with ECT but with a more favorable side effect profile ${ }^{190,191}$.

\section{Vagus nerve stimulation (VNS)}

VNS is a surgically implanted pacemaker-like device attached to a stimulating wire threaded along the left vagus nerve. Since 2005, the FDA has approved VNS use for the adjunctive long-term treatment of long-lasting recurrent depression in patients 18 years and older who are experiencing a major depressive episode and have failed to respond to four or more previous adequate standard antidepressant treatment trials. In such cases, it has been shown to have superior long-term effects over conventional psychopharmacological treatment ${ }^{192}$. A recent, large, observational, adjunctive, open-label, naturalistic study followed TRD patients over 5 years ${ }^{193}$. In this group, adjunctive VNS led to significantly better clinical outcomes and higher remission rates than treatment as usual ( $67.6 \%$ vs. $40.9 \%$, respectively).

\section{Deep-brain stimulation (DBS)}

DBS involves the neurosurgical implantation of electrodes and has become clinically routine in the treatment of Parkinson's disease and Dystonia. The technique is safe, removable, and does not cause lasting neuronal lesions. In TRD, anatomical targets include the subgenual cingulate, nucleus accumbens, habenula, and medial forebrain bundle. Clinical trials typically only enroll severely ill TRD patients whose current episode has lasted $>12$ months, whose age of onset is $<45$ years, and who have failed to respond to at least four adequate prior treatment trials of standard antidepressants, ECT, and/or psychotherapy. Initial open-label or single-blind trials found that DBS had both rapid and sustained antidepressant effects ${ }^{194-196}$. In contrast, one large and one smaller sham-controlled clinical study both failed to achieve their primary endpoints of symptom reduction ${ }^{197,198}$. To date, the number of MDD patients treated with DBS has been very small compared to other treatment options, including ECT and TMS. Nevertheless, brain-electrode interfaces are evolving quickly and it is possible that next generation brain-responsive stimulation devices will be able to adjust stimulation on-demand only when abnormal biological marker impulses (e.g., pulse amplitude) are detected ${ }^{199}$.

\section{Conclusions}

Although enormous progress has been made in measuring, predicting, and improving outcomes, depression remains a relentless disease that places a heavy burden on both individuals and society. The research reviewed above indicates that early recognition and early adequate treatment at illness onset are preferable to watch-and-wait strategies. The studies reviewed above also underscore the manner in which SLEs, as well as physical and psychiatric comorbidities, contribute to impaired outcomes. Together, these factors contribute toward treatment resistance, which has gained a substantial amount of importance as a patient-stratifying variable.

This paper also reviewed biological markers, where research has grown exponentially to encompass enormous projects with potentially tens of thousands of subjects enrolled in real world studies. In parallel, studies exploring the underlying genetics of depression have evolved from early candidate gene studies of neurotransmitters, stress, or gene-regulatory systems to large GWAS that help reveal potential new pathways and treatment targets. Moreover, the burgeoning field of proteomics has found promising target molecules. Nevertheless, despite the wealth of recent work in this area, no single biomarker has yet been used in clinical applications. A substantial need exists for replication and, because many biomarker studies are currently open-label, for controlled studies. In combination with neuroimaging techniques such as fMRI, genes or blood-based markers have a high potential of future implementation in stratification of MDD or serve as prognostic marker on treatment outcome.

Above, we also outlined efforts to optimize outcomes. We argue that disease-inherent heterogeneity, in concert with inaccurate group stratification tools, might have contributed to the lack of clinically applicable stratification and response prediction markers. Successful subgroup identification, and the ability to use this information in clinical settings, is crucial to improving future treatment paradigms. While recent research has increasingly focused on TRD, we wish to reiterate that no standard definition of TRD presently exists. Thus, based on currently available guidelines, we have outlined a sequential treatment optimization scheme that includes options for TRD; such work highlights the substantial 
Table 3 Key points of strategies to improve outcomes in MDD

- Enormous improved outcomes are needed in MDD

- Candidate clinical, neuroimaging, blood, and genetic markers exist but need to be improved to be applicable for routine clinical care

- Early identification and treatment facilitate better outcomes

- The advantages of existing treatments may be harnessed by standardized sequential use

- Novel antidepressants — some with rapid-acting mechanisms-have high potential for approval

- Brain stimulation techniques such as TMS, TBS, ECT, and DBS are evolving and are an important, often underused treatment option

- Treatment strategies for chronic patients exist, but more research needs to focus on "third-line-and-beyond" therapeutics

need to develop and improve "third-line-and-beyond" therapeutics. In this context, this manuscript also reviews novel treatments and brain stimulation techniques that have demonstrated rapid antidepressant effects in TRD, including ketamine, esketamine, ECT, MST, TMS/TBS, VNS, DBS, and others. When treating TRD patients, physicians should consider illness severity, the chronicity of past and recent depressive episodes, the side effect profile of available treatment options, as well as previous refractoriness to particular treatment approaches. If acuity supersedes chronicity, one could consider fast-acting interventions such as ketamine or ECT/MST.

This review, though comprehensive, was not able to consider several lines of evidence on outcome prediction and treatment improvement. In particular, we focused on clinical outcomes in humans and were, thus, unable to fully explore the highly valuable advances made in translational science. Similarly, it was beyond the scope of this manuscript to review the richness of results from animal research and their relevance to MDD. Moreover, given the amount of literature, we were not able to incorporate many proteomic, genetic, or psychopharmacological findings.

Taken together, this review outlines important clinical, psychosocial, and biological factors associated with response and remission to antidepressant treatment (see Table 3). Recent studies have led to important insights into neurobiological disease markers that could result in improved disease stratification and response prediction in the near future. Key discoveries into novel rapid-acting substances, in concert with improvements in brain stimulation techniques, may also result in significantly improved treatment outcomes in formerly hard-to-treat patients.

\section{Acknowledgements}

We thank the 7SE research unit and staff for their support. loline Henter (NIMH) provided invaluable editorial assistance. We also thank E. Acevedo-Diaz, Z.D. Deng, and J.W. Evans for scientific input.

\section{Conflict of interest}

Funding for this work was supported in part by the Intramural Research Program at the National Institute of Mental Health, National Institutes of Health (IRP-NIMH-NIH; ZIA MH002927). All support given to authors was not related to the design of the manuscript or the ideas stated in this review. Dr. Kasper received grants/research support, consulting fees, and/or honoraria within the last 3 years from Angelini, AOP Orphan Pharmaceuticals AG, AstraZeneca, Eli Lilly, Janssen, KRKA-Pharma, Lundbeck, Neuraxpharm, Pfizer, Pierre Fabre, Schwabe, and Servier. Dr. Lanzenberger received travel grants and/or conference speaker honoraria from AstraZeneca, Lundbeck A/S, Dr. Willmar Schwabe GmbH, Orphan Pharmaceuticals AG, Janssen-Cilag Pharma GmbH, and Roche Austria $\mathrm{GmbH}$. Dr. Kraus has received travel grants from Roche Austria GmbH and AOP Orphan. Dr. Zarate is a full-time U.S government employee. He is listed as a co-inventor on a patent for the use of ketamine in major depression and suicidal ideation; as a co-inventor on a patent for the use of $(2 R, 6 R)$-hydroxynorketamine, $(S)$-dehydronorketamine, and other stereoisomeric dehydro and hydroxylated metabolites of $(R, S)$-ketamine metabolites in the treatment of depression and neuropathic pain; and as a coinventor on a patent application for the use of $(2 R, 6 R)$-hydroxynorketamine and $(25,65)$-hydroxynorketamine in the treatment of depression, anxiety, anhedonia, suicidal ideation, and post-traumatic stress disorders. He has assigned his patent rights to the U.S. government but will share a percentage of any royalties that may be received by the government.

\section{Publisher's note}

Springer Nature remains neutral with regard to jurisdictional claims in published maps and institutional affiliations.

Received: 7 November 2018 Revised: 10 January 2019 Accepted: 11 February 2019

Published online: 03 April 2019

\section{References}

1. Wittchen, H. U. et al. The size and burden of mental disorders and other disorders of the brain in Europe 2010. Eur. Neuropsychopharmacol.: J. Eur. Coll. Neuropsychopharmacol. 21, 655-679 (2011).

2. Lim, S. S. et al. A comparative risk assessment of burden of disease and injury attributable to 67 risk factors and risk factor clusters in 21 regions, 1990-2010: a systematic analysis for the Global Burden of Disease Study 2010. Lancet 380, 2224-2260 (2012).

3. Lecrubier, Y. Widespread underrecognition and undertreatment of anxiety and mood disorders: results from 3 European studies. J. Clin. Psychiatry $6 \mathbf{8}$ Suppl 2, 36-41 (2007)

4. Riedel, M. et al. Clinical predictors of response and remission in inpatients with depressive syndromes. J. Affect. Disord. 133, 137-149 (2011).

5. Rost, K. et al. Persistently poor outcomes of undetected major depression in primary care. Gen. Hosp. Psychiatry 20, 12-20 (1998).

6. Ghio, L., Gotelli, S., Marcenaro, M., Amore, M. \& Natta, W. Duration of untreated illness and outcomes in unipolar depression: a systematic review and meta-analysis. J. Affect. Disord. 152-154, 45-51 (2014). 
7. Hung, C. I., Liu, C. Y. \& Yang, C. H. Untreated duration predicted the severity of depression at the two-year follow-up point. PLOS ONE 12, e0185119 (2017).

8. Bukh, J. D., Bock, C., Vinberg, M. \& Kessing, L. V. The effect of prolonged duration of untreated depression on antidepressant treatment outcome. J. Affect. Disord. 145, 42-48 (2013).

9. Habert, J. et al. Functional recovery in major depressive disorder: Focus on early optimized treatment. Prim Care Companion CNS Disord. 18 (2016)

10. Kautzky, A. et al. Clinical factors predicting treatment resistant depression: affirmative results from the European multicenter study. Acta Psychiatr. Scand. 139, 78-88 (2018).

11. Furukawa, T. A., Kitamura, T. \& Takahashi, K. Time to recovery of an inception cohort with hitherto untreated unipolar major depressive episodes. Br. J. Psychiatry:: J. Ment. Sci. 177, 331-335 (2000).

12. Feffer, K. et al. Early symptom improvement at 10 sessions as a predictor of rTMS treatment outcome in major depression. Brain Stimul. 11, 181-189 (2018).

13. Martinez-Amoros, E. et al. Early improvement as a predictor of final remission in major depressive disorder: New insights in electroconvulsive therapy. J. Affect. Disord. 235, 169-175 (2018).

14. Soares, C. N., Endicott, J., Boucher, M., Fayyad, R. S. \& Guico-Pabia, C. J. Predictors of functional response and remission with desvenlafaxine $50 \mathrm{mg} /$ $\mathrm{d}$ in patients with major depressive disorder. CNS Spectr. 19, 519-527 (2014)

15. Lam, R. W. et al. Predictors of functional improvement in employed adults with major depressive disorder treated with desvenlafaxine. Int Clin. Psychopharmacol. 29, 239-251 (2014).

16. Jha, M. K. et al. Early improvement in work productivity predicts future clinical course in depressed outpatients: Findings from the CO-MED trial. Am. J. Psychiatry 173, 1196-1204 (2016).

17. Spies, M. et al. Default mode network deactivation during emotion processing predicts early antidepressant response. Transl. Psychiatry 7, e1008 (2017)

18. Bartlett, E. A. et al. Pretreatment and early-treatment cortical thickness is associated with SSRI treatment response in major depressive disorder. Neuropsychopharmacol.: Off. Publ. Am. Coll. Neuropsychopharmacol. 43 2221-2230 (2018).

19. Olgiati, P. et al. Early improvement and response to antidepressant medications in adults with major depressive disorder. Meta-analysis and study of a sample with treatment-resistant depression. J. Affect Disord. 227, 777-786 (2018).

20. de Vries, Y. A. et al. Predicting antidepressant response by monitoring early improvement of individual symptoms of depression: individual patient data meta-analysis. Br. J. Psychiatry.: J. Ment. Sci. 214, 1-7 (2018)

21. Trivedi, M. H. et al. Evaluation of outcomes with citalopram for depression using measurement-based care in $S T A R^{*} D$ : implications for clinical practice. Am. J. Psychiatry 163, 28-40 (2006).

22. Blom, M. B. et al. Severity and duration of depression, not personality factors, predict short term outcome in the treatment of major depression. J. Affect. Disord. 104, 119-126 (2007).

23. Kautzky, A. et al. Refining prediction in treatment-resistant depression: results of machine learning analyses in the TRD III sample. J. Clin. Psychiatry 79 $16 \mathrm{~m} 11385$ (2018)

24. Katon, W., Unutzer, J. \& Russo, J. Major depression: the importance of clinical characteristics and treatment response to prognosis. Depress Anxiety $\mathbf{2 7}$ 19-26 (2010).

25. Papakostas, G. I. Surrogate markers of treatment outcome in major depressive disorder. Int. J. Neuropsychopharmacol/.Off. Sci. J. Coll. Int. Neuropsychopharmacol. 15, 841-854 (2012).

26. Friedman, E. S. et al. Baseline depression severity as a predictor of single and combination antidepressant treatment outcome: results from the CO-MED trial. Eur. Neuropsychopharmacol.: J. Eur. Coll. Neuropsychopharmacol. 22 183-199 (2012).

27. Balestri, M. et al. Socio-demographic and clinical predictors of treatment resistant depression: A prospective European multicenter study. J. Affect Disord. 189, 224-232 (2016).

28. Souery, D. et al. Clinical factors associated with treatment resistance in major depressive disorder: results from a European multicenter study. J. Clin. Psychiatry 68, 1062-1070 (2007).

29. Mandelli, L. et al. Opinion paper: poor response to treatment of depression in people in high occupational levels. Psychol. Med. 49, 49-54 (2019).
30. Kautzky, A. et al. A new prediction model for evaluating treatment-resistant depression. J. Clin. Psychiatry 78, 215-222 (2017).

31. Paksarian, D. et al. Stability and change in reported age of onset of depression, back pain, and smoking over 29 years in a prospective cohort study. J. Psychiatr. Res. 88, 105-112 (2017).

32. Wells, K. et al. Five-year impact of quality improvement for depression: results of a group-level randomized controlled trial. Arch. Gen. Psychiatry 61, 378-386 (2004).

33. Vinkers, C. H. et al. Stress exposure across the life span cumulatively increases depression risk and is moderated by neuroticism. Depress Anxiety $\mathbf{3 1}$ 737-745 (2014).

34. Kendler, K. S., Kuhn, J. \& Prescott, C. A. The interrelationship of neuroticism, sex, and stressful life events in the prediction of episodes of major depression. Am. J. Psychiatry 161, 631-636 (2004).

35. Nanni, V., Uher, R. \& Danese, A. Childhood maltreatment predicts unfavorable course of illness and treatment outcome in depression: a meta-analysis. Am J. Psychiatry 169, 141-151 (2012).

36. Thompson, A. E. \& Kaplan, C. A. Childhood emotional abuse. Br. J. Psychiatry.: J. Ment. Sci. 168, 143-148 (1996).

37. Nelson, J., Klumparendt, A., Doebler, P. \& Ehring, T. Childhood maltreatment and characteristics of adult depression: meta-analysis. Br. J. Psychiatry.: J. Ment Sci. 210, 96-104 (2017)

38. Kendler, K. S. \& Gardner, C. O. Sex differences in the pathways to major depression: a study of opposite-sex twin pairs. Am. J. Psychiatry 171, 426-435 (2014).

39. Keers, R. et al. Stressful life events, cognitive symptoms of depression and response to antidepressants in GENDEP. J. Affect. Disord. 127, 337-342 (2010).

40. Henriksen, C. A. et al. Identifying factors that predict longitudinal outcomes of untreated common mental disorders. Psychiatr. Serv. 66, 163-170 (2015).

41. Dennehy, E. B., Marangell, L. B., Martinez, J., Balasubramani, G. K. \& Wisniewski, S. R. Clinical and functional outcomes of patients who experience partial response to citalopram: secondary analysis of STAR*D. J. Psychiatr. Pract. 20 178-187 (2014).

42. Dold, M. et al. Clinical characteristics and treatment outcomes of patients with major depressive disorder and comorbid anxiety disorders-results from a European multicenter study. J. Psychiatr. Res. 91, 1-13 (2017).

43. Fava, M. et al. Difference in treatment outcome in outpatients with anxious versus nonanxious depression: a STAR*D report. Am. J. Psychiatry 165 342-351 (2008).

44. Angstman, K. B. et al. Personality disorders in primary care: impact on depression outcomes within collaborative care. J. Prim. Care Community Health 8, 233-238 (2017)

45. Zeeck, A. et al. Prognostic and prescriptive predictors of improvement in a naturalistic study on inpatient and day hospital treatment of depression. J. Affect. Disord. 197, 205-214 (2016).

46. Newton-Howes, G., Tyrer, P. \& Johnson, T. Personality disorder and the outcome of depression: meta-analysis of published studies. Br. J. Psychiatry.: J. Ment. Sci. 188, 13-20 (2006).

47. Whooley, M. A. et al. Depressive symptoms, health behaviors, and risk of cardiovascular events in patients with coronary heart disease. JAMA $\mathbf{3 0 0}$ 2379-2388 (2008).

48. Ducat, L., Philipson, L. H. \& Anderson, B. J. The mental health comorbidities of diabetes. JAMA 312, 691-692 (2014)

49. Fugger, G. et al. Comorbid thyroid disease in patients with major depressive disorder-results from the European Group for the Study of Resistant Depression (GSRD). Eur. Neuropsychopharmacol. 28, 752-760 (2018).

50. Iosifescu, D. V. et al. The impact of medical comorbidity on acute treatment in major depressive disorder. Am. J. Psychiatry 160, 2122-2127 (2003).

51. Oslin, D. W. et al. Association between medical comorbidity and treatment outcomes in late-life depression. J. Am. Geriatr. Soc. 50, 823-828 (2002)

52. Amital, D. et al. Physical co-morbidity among treatment resistant vs. treatment responsive patients with major depressive disorder. Eur. Neu ropsychopharmacol. 23, 895-901 (2013).

53. Karp, J. F. et al. Pain predicts longer time to remission during treatment of recurrent depression. J. Clin. Psychiatry 66, 591-597 (2005).

54. Ohayon, M. M. \& Schatzberg, A. F. Using chronic pain to predict depressive morbidity in the general population. Arch. Gen. Psychiatry 60, 39-47 (2003).

55. Racine, M. Chronic pain and suicide risk: A comprehensive review. Prog. Neuropsychopharmacol. Biol. Psychiatry 87, 269-280 (2018). 
56. Bogner, H. R. et al. The role of medical comorbidity in outcome of major depression in primary care: the PROSPECT study. Am. J. Geriatr. Psychiatry 13, 861-868 (2005).

57. MacQueen, G. M., Yucel, K., Taylor, V. H., Macdonald, K. \& Joffe, R. Posterior hippocampal volumes are associated with remission rates in patients with major depressive disorder. Biol. Psychiatry 64, 880-883 (2008).

58. Phillips, J. L., Batten, L. A., Tremblay, P., Aldosary, F. \& Blier, P. A prospective, longitudinal study of the effect of remission on cortical thickness and hippocampal volume in patients with treatment-resistant depression. Int. J. Neuropsychopharmacol. / Off. Sci. J. Coll. Int. Neuropsychopharmacol. 18 pyv037 (2015).

59. Frodl, T. et al. Effect of hippocampal and amygdala volumes on clinica outcomes in major depression: a 3-year prospective magnetic resonance imaging study. J. Psychiatry Neurosci. 33, 423-430 (2008).

60. Fu, C. H., Steiner, H. \& Costafreda, S. G. Predictive neural biomarkers of clinical response in depression: a meta-analysis of functional and structural neuroimaging studies of pharmacological and psychological therapies. Neurobiol. Dis. 52, 75-83 (2013)

61. Frodl, T. et al. Reduced hippocampal volumes associated with the long variant of the serotonin transporter polymorphism in major depression. Arch. Gen. Psychiatry 61, 177-183 (2004).

62. Vythilingam, M. et al. Hippocampal volume, memory, and cortisol status in major depressive disorder: effects of treatment. Biol. Psychiatry 56, 101-112 (2004).

63. Schmaal, L. et al. Cortical abnormalities in adults and adolescents with major depression based on brain scans from 20 cohorts worldwide in the ENIGMA Major Depressive Disorder Working Group. Mol. Psychiatry 22, 900-909 (2017).

64. Wilkinson, S. T., Sanacora, G. \& Bloch, M. H. Hippocampal volume changes following electroconvulsive therapy: a systematic review and meta-analysis. Biol. Psychiatry Cogn. Neurosci. Neuroimaging 2, 327-335 (2017).

65. Nordanskog, P. et al. Increase in hippocampal volume after electroconvulsive therapy in patients with depression: a volumetric magnetic resonance imaging study. J. ECT 26, 62-67 (2010).

66. Dukart, J. et al. Electroconvulsive therapy-induced brain plasticity determines therapeutic outcome in mood disorders. Proc. Natl Acad. Sci. USA 111 1156-1161 (2014).

67. Gryglewski, G. et al. Structural changes in amygdala nuclei, hippocampal subfields and cortical thickness following electroconvulsive therapy in treatment-resistant depression: longitudinal analysis. Br. J. Psychiatr 214, 159-167 (2019).

68. Oltedal, L. et al. Volume of the human hippocampus and clinical response following electroconvulsive therapy. Biol. Psychiatry 84, 574-581 (2018).

69. Drysdale, A. T. et al. Resting-state connectivity biomarkers define neurophysiological subtypes of depression. Nat. Med. 23, 28-38 (2017).

70. Dunlop, B. W. et al. Functional connectivity of the subcallosal cingulate cortex and differential outcomes to treatment with cognitive-behavioral therapy or antidepressant medication for major depressive disorder. Am. J. Psychiatry 174, 533-545 (2017).

71. Pizzagalli, D. A. et al. Pretreatment rostral anterior cingulate cortex theta activity in relation to symptom improvement in depression: A randomized clinical trial. JAMA Psychiatry 75, 547-554 (2018).

72. Gryglewski, G., Lanzenberger, R., Kranz, G. S. \& Cumming, P. Meta-analysis of molecular imaging of serotonin transporters in major depression. J. Cereb. Blood Flow. Metab. 34, 1096-1103 (2014).

73. Spies, M., Knudsen, G. M., Lanzenberger, R. \& Kasper, S. The serotonin transporter in psychiatric disorders: insights from PET imaging. Lancet Psychiatry 2, 743-755 (2015).

74. Wang, L. et al. Serotonin-1A receptor alterations in depression: a metaanalysis of molecular imaging studies. BMC Psychiatry 16, 319 (2016).

75. Miller, J. M. et al. Brain serotonin $1 \mathrm{~A}$ receptor binding as a predictor of treatment outcome in major depressive disorder. Biol. Psychiatry 74, 760-767 (2013).

76. Miller, J. M., Oquendo, M. A., Ogden, R. T., Mann, J. J. \& Parsey, R. V. Serotonin transporter binding as a possible predictor of one-year remission in major depressive disorder. J. Psychiatr. Res. 42, 1137-1144 (2008).

77. Lanzenberger, R. et al. Prediction of SSRI treatment response in major depression based on serotonin transporter interplay between median raphe nucleus and projection areas. Neurolmage 63, 874-881 (2012).

78. Drevets, W. C. Neuroimaging studies of mood disorders. Biol. Psychiatry 48 813-829 (2000).
79. Kennedy, S. H. et al. Differences in brain glucose metabolism between responders to CBT and venlafaxine in a 16-week randomized controlled trial. Am. J. Psychiatry 164, 778-788 (2007).

80. Setiawan, E. et al. Role of translocator protein density, a marker of neuroinflammation, in the brain during major depressive episodes. JAMA Psychiatry 72, 268-275 (2015)

81. Richards, E. M. et al. PET radioligand binding to translocator protein (TSPO) is increased in unmedicated depressed subjects. EJNMMI Res. 8, 57 (2018).

82. Holmes, S. E. et al. Elevated translocator protein in anterior cingulate in major depression and a role for inflammation in suicidal thinking: a positron emission tomography study. Biol. Psychiatry 83, 61-69 (2018).

83. Wium-Andersen, M. K. Orsted, D. D. \& Nordestgaard, B. G. Elevated plasma fibrinogen, psychological distress, antidepressant use, and hospitalization with depression: two large population-based studies. Psychoneuroendocrinology 38, 638-647 (2013).

84. Jha, M. K. et al. Can C-reactive protein inform antidepressant medication selection in depressed outpatients? Findings from the CO-MED trial. Psychoneuroendocrinology 78, 105-113 (2017).

85. Kohler-Forsberg, O. et al. Association between C-reactive protein (CRP) with depression symptom severity and specific depressive symptoms in major depression. Brain Behav. Immun. 62, 344-350 (2017).

86. Strawbridge, R. et al. Inflammation and clinical response to treatment in depression: A meta-analysis. Eur. Neuropsychopharmacol.: J. Eur. Coll. Neuropsychopharmacol. 25, 1532-1543 (2015).

87. Lamers, F. et al. Serum proteomic profiles of depressive subtypes. Transl. Psychiatry 6, e851 (2016).

88. Kadriu, B. et al. Acute ketamine administration corrects abnormal inflammatory bone markers in major depressive disorder. Mol. Psychiatry 23 1626-1631 (2017).

89. Machado-Vieira, R. et al. The role of adipokines in the rapid antidepressant effects of ketamine. Mol. Psychiatry 22, 127-133 (2017).

90. Schmidt, H. D., Shelton, R. C. \& Duman, R. S. Functional biomarkers of depression: diagnosis, treatment, and pathophysiology. Neuropsychopharmacology 36, 2375-2394 (2011).

91. Molendijk, M. L. et al. Serum BDNF concentrations as peripheral manifestations of depression: evidence from a systematic review and meta-analyses on 179 associations ( $\mathrm{N}=9484$ ). Mol. Psychiatry 19, 791-800 (2014).

92. Brunoni, A. R., Baeken, C., Machado-Vieira, R., Gattaz, W. F. \& Vanderhasselt, M. A. BDNF blood levels after electroconvulsive therapy in patients with mood disorders: a systematic review and meta-analysis. World J. Biol. Psychiatry 15 411-418 (2014)

93. Polyakova, M. et al. BDNF as a biomarker for successful treatment of mood disorders: a systematic \& quantitative meta-analysis. J. Affect. Disord. 174, 432-440 (2015).

94. Wray, N. R. et al. Genome-wide association analyses identify 44 risk variants and refine the genetic architecture of major depression. Nat. Genet. 50, 668-681 (2018).

95. Fabbri, C. et al. Consensus paper of the WFSBP Task Force on Genetics: Genetics, epigenetics and gene expression markers of major depressive disorder and antidepressant response. World J. Biol. Psychiatry 18, 5-28 (2017)

96. Kautzky, A. et al. The combined effect of genetic polymorphisms and clinical parameters on treatment outcome in treatment-resistant depression. Eur. Neuropsychopharmacol. 25, 441-453 (2015).

97. Stamm, T. J. et al. The FKBP5 polymorphism rs1360780 influences the effect of an algorithm-based antidepressant treatment and is associated with remission in patients with major depression. J. Psychopharmacol. 30, 40-47 (2016).

98. Binder, E. B. et al. Polymorphisms in FKBP5 are associated with increased recurrence of depressive episodes and rapid response to antidepressant treatment. Nat. Genet. 36, 1319-1325 (2004).

99. Fabbri, C. et al. Pleiotropic genes in psychiatry: Calcium channels and the stress-related FKBP5 gene in antidepressant resistance. Prog. Neuropsychopharmacol. Biol. Psychiatry 81, 203-210 (2018).

100. Klengel, T. \& Binder, E. B. Gene x environment interactions in the prediction of response to antidepressant treatment. Int. J. Neuropsychopharmacol/Off. Sci. J. Coll. Int. Neuropsychopharmacol. 16, 701-711 (2013).

101. Schosser, A. \& Kasper, S. The role of pharmacogenetics in the treatment of depression and anxiety disorders. Int. Clin. Psychopharmacol. 24, 277-288 (2009). 
102. Zeier, Z. et al. Clinical implementation of pharmacogenetic decision support tools for antidepressant drug prescribing. Am. J. Psychiatry 175, 873-886 (2018).

103. Jukic, M. M., Haslemo, T., Molden, E. \& Ingelman-Sundberg, M. Impact of CYP2C19 genotype on escitalopram exposure and therapeutic failure: A retrospective study based on 2,087 patients. Am. J. Psychiatry 175, 463-470 (2018)

104. Bauer, M. et al. World Federation of Societies of Biological Psychiatry (WFSBP) guidelines for biological treatment of unipolar depressive disorders, part 1 update 2013 on the acute and continuation treatment of unipolar depressive disorders. World J. Biol. Psychiatry 14, 334-385 (2013).

105. Uher, R. et al. Melancholic, atypical and anxious depression subtypes and outcome of treatment with escitalopram and nortriptyline. J. Affect. Disord. 132, 112-120 (2011)

106. Arnow, B. A. et al. Depression subtypes in predicting antidepressant response: A report from the iSPOT-D trial. Am. J. Psychiatry 172, 743-750 (2015).

107. Kasper, S. \& Montgomery, S. A. Ohio Library and Information Network, Wiley Online Library (Online service). Treatment-resistant Depression, 1 online resource (2013).

108. Schosser, A. et al. European Group for the Study of Resistant Depression (GSRD)-where have we gone so far: review of clinical and genetic findings. Eur. Neuropsychopharmacol. 22, 453-468 (2012)

109. Bergfeld, I. O. et al. Treatment-resistant depression and suicidality. J. Affect. Disord. 235, 362-367 (2018)

110. Mann, J. J. et al. Suicide prevention strategies: a systematic review. JAMA 294, 2064-2074 (2005).

111. Nimalasuriya, K., Compton, M. T. \& Guillory, V. J., Prevention Practice Committee of the American College of Preventive M. Screening adults for depression in primary care: A position statement of the American College of Preventive Medicine. J. Fam. Pract. 58, 535-538 (2009).

112. Kroenke, K., Spitzer, R. L. \& Williams, J. B. The Patient Health Questionnaire-2: validity of a two-item depression screener. Med. Care 41, 1284-1292 (2003).

113. Horowitz, L. M. et al. Ask suicide-screening questions to everyone in medical settings: the asQ'em Quality Improvement Project. Psychosomatics 54, 239-247 (2013).

114. King, $M$. et al. Predicting onset of major depression in general practice attendees in Europe: extending the application of the predictD risk algorithm from 12 to 24 months. Psychol. Med. 43, 1929-1939 (2013).

115. Kupfer, D. J., Frank, E. \& Perel, J. M. The advantage of early treatment intervention in recurrent depression. Arch. Gen. Psychiatry 46, 771-775 (1989).

116. Lopizzo, N. et al. Gene-environment interaction in major depression: focus on experience-dependent biological systems. Front. Psychiatry 6, 68 (2015).

117. Gutierrez, B. et al. The risk for major depression conferred by childhood maltreatment is multiplied by BDNF and SERT genetic vulnerability: a replication study. J. Psychiatry Neurosci.: JPN 40, 187-196 (2015).

118. Serretti, A. et al. The impact of adverse life events on clinical features and interaction with gene variants in mood disorder patients. Psychopathology 46, 384-389 (2013)

119. Herbison, C. E., Allen, K., Robinson, M., Newnham, J. \& Pennell, C. The impact of life stress on adult depression and anxiety is dependent on gender and timing of exposure. Dev. Psychopathol. 29, 1443-1454 (2017).

120. Keers, R. \& Uher, R. Gene-environment interaction in major depression and antidepressant treatment response. Curr. Psychiatry Rep. 14, 129-137 (2012).

121. Gold, P. W. \& Chrousos, G. P. Organization of the stress system and its dysregulation in melancholic and atypical depression: high vs low $\mathrm{CRH} / \mathrm{NE}$ states. Mol. Psychiatry 7, 254-275 (2002).

122. Carroll, B. J. et al. A specific laboratory test for the diagnosis of melancholia. Standardization, validation, and clinical utility. Arch. Gen. Psychiatry 38, 15-22 (1981).

123. Musil, R. et al. Subtypes of depression and their overlap in a naturalistic inpatient sample of major depressive disorder. Int. J. Methods Psychiatr. Res. 27 (2018).

124. Angst J., Gamma A., Benazzi F., Ajdacic V., Rossler W. Melancholia and atypical depression in the Zurich study: epidemiology, clinical characteristics, course, comorbidity and personality. Acta Psychiatr. Scand. Suppl. 72-84 (2007).

125. Ionescu, D. F., Niciu, M. J., Henter, I. D. \& Zarate, C. A. Defining anxious depression: a review of the literature. CNS Spectr. 18, 252-260 (2013).

126. Lamers, F. et al. Evidence for a differential role of HPA-axis function, inflammation and metabolic syndrome in melancholic versus atypical depression. Mol. Psychiatry 18, 692-699 (2013).
127. Simmons, W. K. et al. Appetite changes reveal depression subgroups with distinct endocrine, metabolic, and immune states. Mol. Psychiatry, https://doi. org/10.1038/s41380-018-0093-6 (2018).

128. Woody, M. L. \& Gibb, B. E. Integrating NIMH research domain criteria (RDoC) into depression. Res. Curr. Opin. Psychol. 4, 6-12 (2015).

129. Ballard, E. D. et al. Parsing the heterogeneity of depression: An exploratory factor analysis across commonly used depression rating scales. J. Affect. Disord. 231, 51-57 (2018).

130. Ruhe, H. G., van Rooijen, G., Spijker, J., Peeters, F. P. \& Schene, A. H. Staging methods for treatment resistant depression. A systematic review. J. Affect. Disord. 137, 35-45 (2012).

131. Nugent, A. C. et al. Safety of research into severe and treatment-resistant mood disorders: analysis of outcome data from 12 years of clinical trials at the US National Institute of Mental Health. Lancet Psychiatry 3, 436-442 (2016).

132. Herzog, D. P. et al. Guideline adherence of antidepressant treatment in outpatients with major depressive disorder: a naturalistic study. Eur. Arch. Psychiatry Clin. Neurosci. 267, 711-721 (2017).

133. Trivedi, M. H. et al. Clinical results for patients with major depressive disorder in the Texas Medication Algorithm Project. Arch. Gen. Psychiatry 61, 669-680 (2004).

134. Adli, M. et al. How effective is algorithm-guided treatment for depressed inpatients? results from the randomized controlled multicenter german algorithm project 3 trial. Int J. Neuropsychopharmacol. 20, 721-730 (2017)

135. Bauer, M. et al. Efficacy of an algorithm-guided treatment compared with treatment as usual: a randomized, controlled study of inpatients with depression. J. Clin. Psychopharmacol. 29, 327-333 (2009).

136. Ricken, R. et al. Algorithm-guided treatment of depression reduces treatment costs-results from the randomized controlled German Algorithm Project (GAPII). J. Affect. Disord. 134, 249-256 (2011).

137. Khan, A.\& Brown, W. A. Antidepressants versus placebo in major depression: an overview. World Psychiatry 14, 294-300 (2015).

138. Fava, M., Evins, A. E., Dorer, D. J. \& Schoenfeld, D. A. The problem of the placebo response in clinical trials for psychiatric disorders: culprits, possible remedies, and a novel study design approach. Psychother. Psychosom. 72, 115-127 (2003).

139. Enck, P., Bingel, U., Schedlowski, M. \& Rief, W. The placebo response in medicine: minimize, maximize or personalize? Nat. Rev. Drug Discov. 12 191-204 (2013).

140. Desseilles, M. et al. Massachusetts general hospital SAFER criteria for clinical trials and research. Han. Rev. Psychiatry 21, 269-274 (2013).

141. Finniss, D. G., Kaptchuk, T. J., Miller, F. \& Benedetti, F. Biological, clinical, and ethical advances of placebo effects. Lancet 375, 686-695 (2010).

142. Henter, I. D., de Sousa, R. T. \& Zarate, C. A. Jr. Glutamatergic modulators in depression. Harv. Rev. Psychiatry 26, 307-319 (2018).

143. Ionescu, D. F. \& Papakostas, G. I. Current trends in identifying rapidly acting treatments for depression. Curr. Behav. Neurosci. Rep. 3, 185-191 (2016).

144. Kadriu, B. et al. Glutamatergic neurotransmission: pathway to developing novel rapid-acting antidepressant treatments. Int. J. Neuropsychopharmacol. / Off. Sci. J. Coll. Int. Neuropsychopharmacol. 22 119-135 (2018).

145. Zanos, P. et al. Convergent mechanisms underlying rapid antidepressant action. CNS Drugs 32, 197-227 (2018).

146. Li, N. et al. mTOR-dependent synapse formation underlies the rapid antidepressant effects of NMDA antagonists. Science 329, 959-964 (2010).

147. Autry, A. E. et al. NMDA receptor blockade at rest triggers rapid behavioural antidepressant responses. Nature 475, 91-95 (2011)

148. Berman, R. M. et al. Antidepressant effects of ketamine in depressed patients. Biol. Psychiatry 47, 351-354 (2000)

149. Duman, R. S. \& Aghajanian, G. K. Synaptic dysfunction in depression: potential therapeutic targets. Science 338, 68-72 (2012).

150. Diazgranados, N. et al. Rapid resolution of suicidal ideation after a single infusion of an N-methyl-D-aspartate antagonist in patients with treatment-resistant major depressive disorder. J. Clin. Psychiatry 71, 1605-1611 (2010).

151. ladarola, N. D. et al. Ketamine and other N-methyl-D-aspartate receptor antagonists in the treatment of depression: a perspective review. Ther. Adv Chronic Dis. 6, 97-114 (2015). 
152. Ibrahim, L. et al. Rapid decrease in depressive symptoms with an N-methyl-daspartate antagonist in ECT-resistant major depression. Progress. neuroPsychopharmacol. Biol. Psychiatry 35, 1155-1159 (2011).

153. Zarate, C. A. et al. A randomized trial of an N-methyl-D-aspartate antagonist in treatment-resistant major depression. Arch. Gen. Psychiatry 63, 856-864 (2006).

154. Diazgranados, N. et al. A randomized add-on trial of an N-methyl-D-aspartate antagonist in treatment-resistant bipolar depression. Arch. Gen. Psychiatry 67, 793-802 (2010).

155. Zarate, C. A. et al. Replication of ketamine's antidepressant efficacy in bipolar depression: a randomized controlled add-on trial. Biol. Psychiatry 71, 939-946 (2012).

156. aan het Rot, $M$. et al. Safety and efficacy of repeated-dose intravenous ketamine for treatment-resistant depression. Biol. Psychiatry 67, 139-145 (2010).

157. Wan, L. B. et al. Ketamine safety and tolerability in clinical trials for treatmentresistant depression. J. Clin. Psychiatry 76, 247-252 (2015).

158. Murrough, J. W. et al. Rapid and longer-term antidepressant effects of repeated ketamine infusions in treatment-resistant major depression. Biol. Psychiatry 74, 250-256 (2013)

159. Murrough, J. W. et al. Ketamine for rapid reduction of suicidal ideation: a randomized controlled trial. Psychol. Med. 45, 3571-3580 (2015).

160. Price, R. B., Nock, M. K., Charney, D. S. \& Mathew, S. J. Effects of intravenous ketamine on explicit and implicit measures of suicidality in treatmentresistant depression. Biol. Psychiatry 66, 522-526 (2009).

161. Wilkinson, S. T. et al. The effect of a single dose of intravenous ketamine on suicidal ideation: a systematic review and individual participant data metaanalysis. Am. J. Psychiatry 175, 150-158 (2018).

162. Daly, E. J. et al. Efficacy and safety of intranasal esketamine adjunctive to oral antidepressant therapy in treatment-resistant depression: A randomized clinical trial. JAMA Psychiatry 75, 139-148 (2018).

163. Canuso, C. M. et al. Efficacy and safety of intranasal esketamine for the rapid reduction of symptoms of depression and suicidality in patients at imminent risk for suicide: results of a double-blind, randomized, placebo-controlled study. Am. J. Psychiatry 175, 620-630 (2018)

164. Zanos, P. et al. The prodrug 4-chlorokynurenine causes ketamine-like antidepressant effects, but not side effects, by NMDA/glycineB-site inhibition. J. Pharmacol. Exp. Ther. 355, 76-85 (2015).

165. Wilkinson, S. T. \& Sanacora, G. A new generation of antidepressants: an update on the pharmaceutical pipeline for novel and rapid-acting therapeutics in mood disorders based on glutamate/GABA neurotransmitter systems. Drug Discov. Today 24, 606-615 (2018)

166. Vollenweider, F. X. \& Kometer, M. The neurobiology of psychedelic drugs: implications for the treatment of mood disorders. Nat. Rev. Neurosci. 11 642-651 (2010)

167. Carhart-Harris, R. L. et al. Psilocybin with psychological support for treatmentresistant depression: an open-label feasibility study. Lancet Psychiatry $\mathbf{3}$ 619-627 (2016)

168. Karp, J. F. et al. Safety, tolerability, and clinical effect of low-dose buprenorphine for treatment-resistant depression in midlife and older adults. J. Clin. Psychiatry 75, e785-e793 (2014)

169. Fava, M. et al. Opioid modulation with buprenorphine/samidorphan as adjunctive treatment for inadequate response to antidepressants: A randomized double-blind placebo-controlled trial. Am. J. Psychiatry 173, 499-508 (2016)

170. Preskorn, S. et al. Randomized proof of concept trial of GLYX-13, an Nmethyl-D-aspartate receptor glycine site partial agonist, in major depressive disorder nonresponsive to a previous antidepressant agent. J. Psychiatr. Pract. 21, 140-149 (2015).

171. Garay, R. P. et al. Investigational drugs in recent clinical trials for treatmentresistant depression. Expert Rev. Neurother. 17, 593-609 (2017).

172. Kolbinger, H. M., Hoflich, G., Hufnagel, A., Moller, H. J. \& Kasper, S. Transcrania magnetic stimulation (TMS) in the treatment of major depression-a pilot study. Human. Psychopharmacol. 10, 305-310 (1995).

173. Lisanby, S. H. et al. Daily left prefrontal repetitive transcranial magnetic stimulation in the acute treatment of major depression: clinical predictors of outcome in a multisite, randomized controlled clinica trial. Neuropsychopharmacol.: Off. Publ. Am. Coll. Neuropsychopharmacol. 34, 522-534 (2009).
174. Brunoni, A. R. et al. Repetitive transcranial magnetic stimulation for the acute treatment of major depressive episodes: A systematic review with network meta-analysis. JAMA Psychiatry 74, 143-152 (2017).

175. Benadhira, R. et al. A randomized, sham-controlled study of maintenance rTMS for treatment-resistant depression (TRD). Psychiatry Res 258, 226-233 (2017).

176. Cusin, C. \& Dougherty, D. D. Somatic therapies for treatment-resistant depression: ECT, TMS, VNS, DBS. Biol. Mood Anxiety Disord. 2, 14 (2012).

177. Blumberger, D. M. et al. Effectiveness of theta burst versus high-frequency repetitive transcranial magnetic stimulation in patients with depression (THREE-D): a randomised non-inferiority trial. Lancet 391, 1683-1692 (2018).

178. Fava, M. Diagnosis and definition of treatment-resistant depression. Biol. Psychiatry 53, 649-659 (2003).

179. Husain, M. M. et al. Speed of response and remission in major depressive disorder with acute electroconvulsive therapy (ECT): a Consortium for Research in ECT (CORE) report. J. Clin. Psychiatry 65, 485-491 (2004).

180. Kellner, C. H. et al. Relief of expressed suicidal intent by ECT: a consortium for research in ECT study. Am. J. Psychiatry 162, 977-982 (2005).

181. Slade, E. P., Jahn, D. R., Regenold, W. T. \& Case, B. G. Association of electroconvulsive therapy with psychiatric readmissions in US hospitals. JAMA Psychiatry 74, 798-804 (2017).

182. Kellner, C. H. et al. Right unilateral ultrabrief pulse ECT in geriatric depression: phase 1 of the PRIDE study. Am. J. Psychiatry 173, 1101-1109 (2016)

183. McClintock, S. M. et al. Multifactorial determinants of the neurocognitive effects of electroconvulsive therapy. J. ECT 30, 165-176 (2014).

184. Fink, M. \& Taylor, M. A. Electroconvulsive therapy: evidence and challenges JAmA 298, 330-332 (2007).

185. American Psychiatric Association. Task Force on Electroconvulsive Therapy The practice of ECT: recommendations for treatment, training and privileging. Convuls. Ther. 6, 85-120 (1990).

186. Kellner, C. H. et al. Bifrontal, bitemporal and right unilateral electrode placement in ECT: randomised trial. Br. J. Psychiatry.: J. Ment. Sci. 196, 226-234 (2010).

187. Wilkinson, S. T., Agbese, E., Leslie, D. L. \& Rosenheck, R. A. Identifying recipients of electroconvulsive therapy: data from privately insured Americans. Psychiatr. Sen. 69, 542-548 (2018).

188. Lisanby, S. H., Schlaepfer, T. E., Fisch, H. U. \& Sackeim, H. A. Magnetic seizure therapy of major depression. Arch. Gen. Psychiatry 58, 303-305 (2001).

189. Deng, Z. -D., Lisanby, S. H. \& Peterchev, A. V. Electric field strength and focality in electroconvulsive therapy and magnetic seizure therapy: a finite element simulation study. J. Neural Eng. 8, 016007 (2011).

190. Fitzgerald, P. B. et al. Pilot study of the clinical and cognitive effects of highfrequency magnetic seizure therapy in major depressive disorder. Depress Anxiety 30, 129-136 (2013).

191. Kayser, S. et al. Magnetic seizure therapy in treatment-resistant depression: clinical, neuropsychological and metabolic effects. Psychol. Med. 45, 1073-1092 (2015).

192. Nahas, Z. et al. Two-year outcome of vagus nerve stimulation (VNS) for treatment of major depressive episodes. J. Clin. Psychiatry 66, 1097-1104 (2005)

193. Aaronson, S. T. et al. A 5-Year observational study of patients with treatmentresistant depression treated with vagus nerve stimulation or treatment as usual: comparison of response, remission, and suicidality. Am. J. Psychiatry 174, 640-648 (2017)

194. Schlaepfer, T. E., Bewernick, B. H., Kayser, S., Madler, B. \& Coenen, V. A. Rapid effects of deep brain stimulation for treatment-resistant major depression. Biol. Psychiatry 73, 1204-1212 (2013).

195. Bewernick, B. H. et al. Nucleus accumbens deep brain stimulation decreases ratings of depression and anxiety in treatment-resistant depression. Biol. Psychiatry 67, 110-116 (2010).

196. Bergfeld, I. O et al. Deep brain stimulation of the ventral anterior limb of the internal capsule for treatment-resistant depression: A randomized clinical trial. JAMA Psychiatry 73, 456-464 (2016).

197. Dougherty, D. D. et al. A randomized sham-controlled trial of deep brain stimulation of the ventral capsule/ventral striatum for chronic treatmentresistant depression. Biol. Psychiatry 78, 240-248 (2015).

198. Holtzheimer, P. E. et al. Subcallosal cingulate deep brain stimulation for treatment-resistant depression: a multisite, randomised, sham-controlled trial. Lancet Psychiatry 4, 839-849 (2017). 
199. Widge, A. S., Malone, D. A. Jr. \& Dougherty, D. D. Closing the loop on deep brain stimulation for treatment-resistant depression. Front Neurosci. 12, 175 (2018).

200. Jain, K. K. in The Handbook of Biomarkers. 1-26 (Springer New York, New York NY, 2017).

201. Zohar, J. et al. A review of the current nomenclature for psychotropic agents and an introduction to the Neuroscience-based Nomenclature. Eur. Neuropsychopharmacol.: J. Eur. Coll. Neuropsychopharmacol. 25, 2318-2325 (2015).
202. Dold, M. \& Kasper, S. Evidence-based pharmacotherapy of treatment-resistant unipolar depression. Int J. Psychiatry Clin. Pract. 21, 13-23 (2017).

203. Colle, R. et al. BDNF/TRKB/P75NTR polymorphisms and their consequences on antidepressant efficacy in depressed patients. Pharmacogenomics 16 997-1013 (2015).

204. Porcelli, S., Fabbri, C. \& Serretti, A. Meta-analysis of serotonin transporter gene promoter polymorphism (5-HTTLPR) association with antidepressant efficacy. Eur. Neuropsychopharmacol.: J. Eur. Coll. Neuropsychopharmacol. 22, 239-258 (2012). 